PEDRO ÁlVAREZ CASELLI

ESCUELA DE DISEÑO

FACULTAD DE ARQUITECTURA,

DISEÑO Y ESTUDIOS URBANOS

PONTIFICIA UNIVERSIDAD CATÓLICA DE CHILE

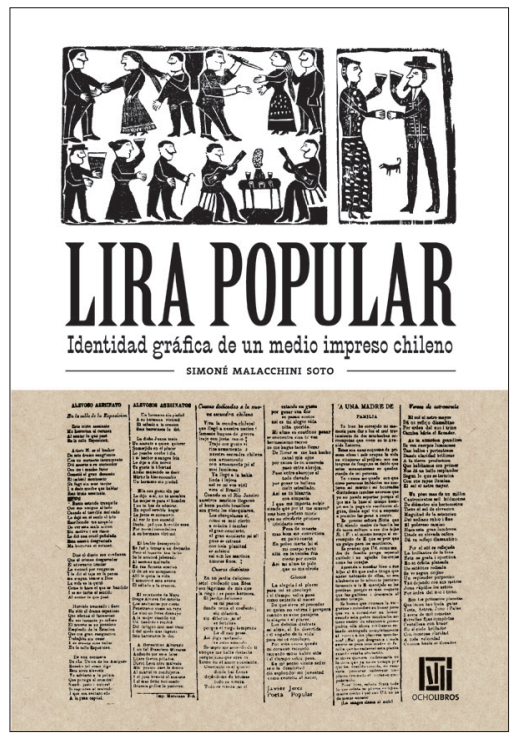

Título: Lira Popular. Identidad gráfica de un medio impreso chileno

Autora: Simoné Malacchini Soto

Editorial: Ocho Libros Editores

Número de páginas: 164

Año Publicación: 2015

ISBN: 978-956-33-5229-0

\section{Lira Popular: identidad gráfica de un medio impreso chileno}

\author{
Lira Popular: Graphic Identity of a Chilean Print Medium
}

Los "buenos versos" - en palabras de Micaela Navarrete- que desde hace aproximadamente dos décadas han comenzado a despertar el entusiasmo por estudiar el fenómeno cultural y social de la literatura de cordel o Lira Popular, como comúnmente se le identifica en Chile, son el centro de atención de esta publicación y generosa investigación desarrollada por Simoné Malacchini. Un marinero chileno mata a una gringa por amor es el título de un pliego suelto, en clave de décima, donde un poeta denuncia un suceso poco feliz, tal como en la actualidad nos enteramos de diversos tipos de crímenes, delitos y cuasi delitos en medios de prensa online, radio, televisión y, cada vez menos, en periódicos impresos. Esta forma testimonial espontánea de las mentalidades y acontecimientos de la vida cotidiana que poblaron el imaginario popular decimonónico y también de los inicios del siglo xx, por medio de la edición de modestas xilografías impresas, ha sido examinada desde el enfoque de diversas disciplinas, particularmente la antropología, la historia y la literatura.

En este sentido, el libro Lira Popular: identidad gráfica de un medio impreso chileno ofrece una nueva perspectiva -en atención a una fuente documental donde todavía queda mucho por explorar-, que se desmarca del estudio del contenido mismo de la poesía o la compleja datación de los pliegos, para adentrarse en el microcosmos de la producción material y el proceso de edición, impresión y distribución de los pliegos en tanto producciones destinadas a un público, en general, escasamente alfabetizado.

De ahí la importancia de la imagen, como evidencia histórica y herramienta auxiliar para la reconstrucción de formas y espacios de producción, representaciones de la técnica y hábitos locales de expresión. Por ello, la investigación también se hace cargo de la utilización de estos grabados populares como fragmentos visuales deslocalizados y extraídos de su contexto original, asumiendo el rol de identificadores gráficos de una suerte de "chilenidad" depositada en bienes de consumo.

Si bien la cuidada edición de Malacchini reconoce nexos con la historia cultural, también se hace evidente la mirada desde el diseño, particularmente en el acercamiento a aspectos formales tales como el uso del papel y la tinta o la manera de diagramar y sacar partido a los clichés tipográficos y especímenes de imprenta. Ello, ciertamente, otorga a esta publicación un grado de novedad y aporte respecto de lo ya realizado en torno a este fascinante tema. 